\title{
Nutritional Training Increases Long-term Fruit and Vegetable Consumption in Women with Early Breast Cancer - A Randomized Controlled Trial
}

Authors

Affiliation
J. Arends, S. Theobald, J. Schmid, H. H. Bartsch

Tumor Biology Center at Freiburg University, Freiburg, Germany

\author{
Key words \\ - breast neoplasms \\ - rehabilitation \\ - Mediterranean diet \\ health promotion \\ - patient participation
}

received 16.07.2014

accepted 30.10.2014

\section{Bibliography \\ DOI http://dx.doi.org/ \\ 10.1055/s-0034-1395671 \\ Published online: \\ December 5, 2014 \\ Metab Nutr Oncol 2014; \\ 2: e1-e7 @ Georg Thieme \\ Verlag KG Stuttgart · New York \\ eISSN 2194-735X}

\section{Correspondence}

\section{Jann Arends, MD}

Tumor Biology Center at

Freiburg University

Breisacher Straße 117

79106 Freiburg

Germany

Tel.: + 49/761/206 1801

Fax: +49/761/206 1892

arends@tumorbio.uni-freiburg.

de

\section{License terms}



\section{Abstract}

$\nabla$

After primary treatment of early breast cancer many women want to change their dietary habits and this may influence disease recurrence. The aim of the study was to increase fruit and vegetable (FV) intake for at least 6 months in women with early breast cancer by a short modular nutritional training program and offering refresher sessions. Design: Single-centre randomized controlled study in women attending an in-hospital cancer rehabilitation program. Subjects in the intervention group (INT) participated in a 2-week structured nutritional training program and were invited to visit brief refresher courses after 3 and 6 months. Women in the control group (CON) were offered standard nutritional advice. All subjects completed 4-day food

\begin{tabular}{ll}
\hline Abbreviations \\
INT & intervention group \\
CON & $\begin{array}{l}\text { control group } \\
\text { FV }\end{array}$ \\
TFV & $\begin{array}{l}\text { intake of fruits and vegetables } \\
\text { including juices and jams }\end{array}$ \\
T1-T4 & $\begin{array}{l}\text { study time points } 1 \text { to } 4\end{array}$
\end{tabular}

\section{Introduction}

$\nabla$

Breast cancer is still a formidable disease with high incidence and recurrence rates after primary treatment of above 20\% [1]. Cancer prevention as well as prevention of recurrence after primary treatment, therefore, ranges high in priority of anti-cancer strategies. Data accumulating during the last decade increasingly outline the relevance of lifestyle factors for cancer incidence [2]. Thus, specific components of lifestyle have been associated with a decreased incidence of breast cancer and of breast cancer recurrence records before arrival (baseline), and 1, 3 and 6 months after the start of the study. Of 152 women included in the study complete follow-up was available for 118 . Consumption of FV (mean \pm SD) was similar at baseline (INT $483 \pm 235$, CON $460 \pm 177 \mathrm{~g} / \mathrm{d}$ ) but only increased in the intervention group and at all follow-up times ( 1 month: $743 \pm 287$ vs. $526 \pm 177$; 3 months: $673 \pm 246$ vs. $485 \pm 169$; 6 months: $631 \pm 222$ vs. $505 \pm 172 \mathrm{~g} / \mathrm{d}$; $\mathrm{p}<0.001)$. There was no discernible effect of the refresher courses on FV intake. There was no relevant effect of intervention on energy and fat intake. A short modular nutritional training program increases FV intake in breast cancer survivors for at least 6 months. This program can be easily implemented and may be combined with other training programs to comprehensively modulate lifestyle.

[3-7], while deranged energy metabolism and the metabolic syndrome may well be major contributors to cancer progression $[8,9]$.

The most important protective factors for several types of cancer appear to be regular muscular activity, a preference for plant foods and the avoidance of high-energy foods and these have been suggested to be incorporated into worldwide teaching and training programs [2]. The evidence for an impact of nutritional factors on breast cancer is inhomogeneous $[8,10,11]$. Analysis of the EPIC study data showed no effect of vegetable and fruit intake on breast cancer risk [12]; however, more recent studies observed a protective effect of consumption of plant foods on breast cancer recurrence $[7,13,14]$. Similarly, an association has been shown between a diet rich in plant foods and a lower risk of metabolic syndrome $[15,16]$. In addition, many women with early breast cancer want to modify their lifestyle after cancer diagnosis including changing their dietary habits to improve health and quality of life $[17,18]$. A recent German survey 
found that the dietary intake in women with early breast cancer deviates far from most recent recommendations for a protective dietary composition [19].

Since there is a lack of structured educational programs for breast cancer patients in Germany, we designed in a modular approach separate programs for exercise and nutrition training in women with early breast cancer. We report here on the development and the effects of a 2-week intensive nutritional training program aimed primarily at strengthening nutritional preferences for plant foods.

\section{Subjects and Methods \\ $\nabla$ \\ Study design and recruitment}

The study was designed as a randomized controlled trial to test the effect of a 2-week nutritional training program (INT, intervention) on the long-term intake of plant foods. The training program was offered to women with early breast cancer during a 3-4 week in-hospital rehabilitation program. The training program was followed by 2 half-day refresher seminars 3 and 6 months after inclusion into the study. The effect of the intervention was compared to the standard of care, including nutritional advice, offered to all patients during the rehabilitation program. The randomization procedure was arrival of participants at Tumor Biology Center during even- or odd-numbered weeks. The study was reviewed by and the procedures followed were found to be in accordance with the ethical standards of the responsible institutional committee on human experimentation.

The primary objective was to increase the intake of fruit and vegetables in women with early breast cancer for at least 6 months by the 2 -week training program. The secondary objectives were A) to increase for 6 months the percentage of patients who reach a fruit and vegetable intake of $650 \mathrm{~g} / \mathrm{d}$ as recommended by the German Nutrition Society (DGE) to reduce primary cancer risk [20]; and B) to judge the effect of the refresher seminars on the long-term effect of the training program. Quantification of dietary intake was done by analysis of 4-day food records at baseline and 1, 3 and 6 months later.

Earlier data had shown that the intake of fruit and vegetables as measured in patients at our institution varies with a standard deviation of $250 \mathrm{~g} / \mathrm{d}$ and increases by about $50 \mathrm{~g} / \mathrm{d}$ during the normal 3-4-week rehabilitation program. We aimed for an increase in the fruit and vegetable intake in the intervention group of $200 \mathrm{~g} / \mathrm{d}$. The sample size needed to detect this difference at the level of $\alpha=0.01$ and to allow for a power of $(1-\beta)=0.90$ was 47 subjects per group. Since we expected a drop-out rate of $33 \%$ until the end of the study, we aimed at including a total of at least 141 patients.

An invitation letter to participate in the study was sent to all women who had finished primary breast cancer treatment and who were waiting to participate in our in-hospital rehabilitation program within the following 4 weeks. The invitation was accompanied by a specially designed protocol booklet and we asked the women to keep a self-administered 4-day food record within the 2 weeks before arrival at our hospital.

Study requirements for all patients were: arriving at our center with a complete 4-day food record; completing a questionnaire on nutritional habits and social situation at entry and after 1 month; and preparing complete 4-day food records for followup at 1, 3 and 6 months after entering the study. Additionally it was required for subjects in the intervention group to participate in the 2-week nutrition training course;
After admittance to the Tumor Biology Center all patients were interviewed, underwent a routine medical examination and the body weight was measured with a calibrated scale. After giving informed consent patients were included according to inclusion and exclusion criteria. Inclusion criteria were: female sex, age 18-70 years, early breast cancer after curative treatment, willingness to participate in the 6 -months program. Exclusion criteria: breast cancer recurrence, presence of active secondary cancer, relevant food allergies, smoking, presence of severe disease that would impair participation in the program, inability to comprehend or appraise the implications of participation. After entering the study, further exclusion criteria were: participation in less than 7 out of 8 units of the 2-week training course, and presenting less than the required 4 complete 4-day food records. The random assignment to the intervention (INT) or to the control group (CON) was performed according to the calendar week. Patients arriving in odd calendar weeks were automatically assigned to the INT and patients arriving in even calendar weeks were assigned to the control group (CON). The nutritional training program was presented during the first 2.5 weeks of the usual 3-4 week duration of the rehabilitation program. On the last day of the rehab-program body weight was measured again.

\section{Nutritional training program and standard nutritional advice}

The nutritional training program was developed as a structured program at our institution for groups of 5-10 women and was tested on 2 pilot groups. The program consisted of six $90-\mathrm{min}$ units of theory and two $3 \frac{1}{2}-\mathrm{h}$ cookery classes; both types of components were designed with an emphasis on motivation and practical advice for the individual patients' situation at home. The methodical elements of the units included hand-out material, workshops, sensory tests, short lectures, and discussion forums as well as exercises to practice the acquired knowledge. The program focused on increasing the intake of fruit and vegetables but also focused on increasing whole meal products and reducing fats and meat consumption. Weight reduction, although expected due to modification of dietary habits, was not an objective of this study.

The Department of Nutrition and Metabolism at Tumor Biology Center Freiburg offers a range of voluntary counseling services to all patients including weekly lectures, open workshops, discussion groups, cookery classes and according to medical needs individual nutritional counseling. Patients of both INT and CON groups were free to benefit from this standard program.

\section{Refresher courses}

Additional components of the intervention program were 2 halfday refresher courses 3 and 6 months after entering the study. These courses were designed to re-motivate the participants and to discuss possible problems of implementing new habits in the domestic environment. All participants in the intervention group were offered to attend any of 2 scheduled half-day refresher courses, with travel costs and accommodation covered by Tumor Biology Center. Patients who had participated together in the same training group were invited together as a group to the refresher courses. These courses were scheduled to take place 13 (refresher course 1) and 25 (course 2) weeks after the initial program. Participants in the refresher courses were required to keep the food records T3 and T4 within the week after the date of the respective refresher course. 


\section{Dietary assessment}

Self-administered food records are recognized as the gold standard for measuring individual dietary habits due to high precision in quantifying the ingested amount of various foods [21]. However, due to the time requirements for the patient and the researcher this instrument is mainly used in smaller study populations. Food frequency questionnaires and repeated $24 \mathrm{~h}$-recalls are more common, particularly in larger samples. These latter instruments show similar but relevant measurement errors due to various reasons, e.g. intentional or unconscious underreporting (regarding fat consumption), over reporting, compliance [22]. We chose the more laborious but also more accurate method of 4-day food records for assessing dietary intake, since we did not obtain additional parameters of nutritional intake, e.g. plasma carotenoid concentrations.

4 separate and complete 4-day food records had to be prepared by all study participants: 1 ) within 2 weeks before arrival at Tumor Biology Center ( $\mathrm{t} 1=$ baseline), 2 ) within the 2 weeks after rehabilitation ( $\mathrm{t} 2=1$ month), 3 ) 3 months after entering the study ( $t 3=3$ months/within 1 week of refresher course 1 ) and 4 ) 6 months after entering the study ( $t 4=6$ months/within 1 week after refresher course 2).

All participants received special 4-day food record booklets including a detailed manual with an example of a food record as well as examples of portion sizes and weights for most of the common foods and beverages. Foods and drinks were counted in common measures, e. g. spoons, cups, glasses, handful etc. Mixed dishes had to be divided into single components and measured separately. Brands of ready to eat manufactured foods had to be listed in the record. The food records covered 3 consecutive weekdays and 1 weekend day (i.e., either from Sunday to Wednesday or from Wednesday to Saturday). All food intake data presented in this paper represent means of the 4 recorded days.

\section{Food data analysis}

The data were analyzed by trained nutritionists blinded to the study arm of the patients (INT or CON) with PRODI 4.5 compact, a nutritional computing and counseling program based on the German Federal Food Database ("Bundeslebensmittelschluessel") version II.3 extract, which contains complete data sets of 30 nutrients in 1600 single foods, food compositions and recipes [23]. The database is able to calculate single nutrients as well as amounts of a food group (e.g. fruit, vegetables, potato products, meat, meat products, etc.). The values of the food records were entered by a skilled dietician. With PRODI imprecise portion descriptions in the patient's food record can be replaced by weighted mean portion sizes to prevent missing data.

It is important to note, that in PRODI 4.5 within the food group "fruit" not only raw and cooked fruit and juices but also jams are included. However, since the ingested amounts of jams were generally small, it is unlikely that they influenced the value of total fruit significantly. Similarly the food group "vegetables" includes raw and cooked vegetables as well as vegetable juices. We used calculations of raw and cooked fruit and vegetables $(=\mathrm{FV})$ to estimate "fruit and vegetable intake" as presented in the primary study objective. In addition we calculated and presented total intake of fruit and vegetables including juices and jams (=TFV).

\section{Statistics}

Descriptive statistics were calculated for all relevant variables. If not mentioned otherwise data are displayed as means \pm SD. The graphical time course of intake of FV and TFV is shown as means \pm SEM. The major study objective was to increase FV intake. Two-way repeated measures ANOVA with one factor repetition was used to test for differences in FV intake and post hoc pairwise comparisons were performed according to the HolmSidak method. All further statistical testing was exploratory:

Differences in TFV, total energy and fat intake were analyzed with ANOVA as described above; Student's t-test was used to test for differences in FV intake in participants attending or not attending a refresher course; and Wilcoxon's test was used to test for differences between the groups regarding the percentages of patients reporting to consume more than the recommended amount of $650 \mathrm{~g} / \mathrm{d}$ of FV. All statistical analyses were performed using the software "Statistical Package for Social Sciences" (SPSS), version 11.5.1 [24].

\section{Results}

\section{$\nabla$}

Of the 222 patients invited by mail to participate in the study, 32 declined to prepare a food record, 3 presented inadequate food records and 35 did not meet the inclusion criteria when arriving at Tumor Biology Center. Of the remaining 152 patients 81 arrived in odd-numbered weeks and 71 arrived in even-numbered weeks. 5 patients in each group declined participation in the study when confronted with the study protocol. Thus we included 76 patients in the intervention group and 66 patients in the control group ( $\bullet$ Fig. 1). Recruitment was stopped when more than 140 patients had been included into the program. In the intervention group during follow-up 15 patients did not prepare all required food records and dropped out before the end of the study. In the control group 9 patients dropped out. 45 and 29 patients of the intervention group attended the refresher courses at 3 and 6 months, respectively. Final analysis was on 61 patients in the intervention group and 57 control patients.

\section{Patient characteristics}

All patients included had completed primary treatment of their breast cancer and had no residual or recurrent disease. Patients in both groups did not differ with respect to age, height or weight ( $\odot$ Table 1). Time since cancer diagnosis ranged from less than 3 to more than 12 months with the median at 6-12 months; the distribution of the intervals was similar in both groups. More than $80 \%$ of subjects had undergone adjuvant radiotherapy and two thirds of subjects in both groups had received adjuvant chemotherapy. Drop-outs had no distorting effect on these parameters. Both groups also were similar with respect to all social characteristics obtained at study entry ( $\bullet$ Table 2 ). After 1 month (T2) a larger fraction of patients in the intervention group reported a change in eating habits. BMI was similar in both groups at baseline and after 1 month, while data on body weight at 3 and 6 months were not available.

\section{Fruit and vegetable (FV) intake}

The primary objective of intervention aim was an increase in FV intake at 1, 3 and 6 months. $\odot$ Table 3 shows that mean daily intakes of $\mathrm{FV}$ in the intervention group increased at all time points when compared to the baseline level, while there was no significant change in the control group. At T2, T3 and T4 the FV intake in the intervention group was large than in the control group. Reported FV intake was highest directly after the training program at $\mathrm{T} 2$ and declined significantly again at $\mathrm{T} 3$ without fur- 




Table 1 Patient characteristics and pre-treatment.

\begin{tabular}{|c|c|c|}
\hline & $\begin{array}{l}\text { Intervention group * } \\
{[n=61]}\end{array}$ & $\begin{array}{l}\text { Control group * } \\
{[n=57]}\end{array}$ \\
\hline age [years] & $51.4 \pm 10.2$ & $54.6 \pm 9.0$ \\
\hline height [m] & $1.66 \pm 0.06$ & $1.64 \pm 0.06$ \\
\hline BMI at $\mathrm{T} 1\left[\mathrm{~kg} / \mathrm{m}^{2}\right]$ & $24.3 \pm 4.1$ & $24.4 \pm 4.3$ \\
\hline BMI at $\mathrm{T} 2\left[\mathrm{~kg} / \mathrm{m}^{2}\right]$ & $24.3 \pm 4.0$ & $24.0 \pm 3.8$ \\
\hline \multicolumn{3}{|l|}{ time since diagnosis } \\
\hline$<3$ months $(n)$ & 2 & 2 \\
\hline 3-6 months (n) & 17 & 20 \\
\hline $6-12$ months (n) & 28 & 28 \\
\hline$>12$ months (n) & 14 & 7 \\
\hline previous adjuvant radiotherapy & $\mathrm{n}=52(85 \%)$ & $\mathrm{n}=52(91 \%)$ \\
\hline previous adjuvant chemotherapy & $\mathrm{n}=39(64 \%)$ & $\mathrm{n}=38(67 \%)$ \\
\hline
\end{tabular}

ther change at T4 and without reaching the baseline level. The maximal increase in FV intake at T2 was $260 \mathrm{~g} / \mathrm{d}(+54 \%)$ in the intervention group, while FV intake at $\mathrm{T} 2$ increased not significantly by $66 \mathrm{~g} / \mathrm{d}$ in the control group, similar to the value projected at study conception. The mean FV intake in the intervention group reached the recommended level $(\geq 650 \mathrm{~g} / \mathrm{d})$ at 1 month and 3 months but not at 6 months, while the mean control values always remained below this level.

\section{Total fruit and vegetable intake}

Fruit and vegetable juices contribute to the total amount of fruit and vegetable intake. They are sometimes recommended as a first step to increase the intake of plant foods, although juices usually contain less bioactive ingredients and fiber than the foods from whole plants. The parameter TFV includes FV as defined above, but also includes fruit and vegetable juices $(100 \%$ juice) as well as jam intake (minimum fruit content: $50 \%$ ).

\begin{tabular}{|c|c|c|}
\hline & $\begin{array}{l}\text { Intervention group } \\
\qquad \mathbf{n = 6 1}\end{array}$ & $\begin{array}{l}\text { Control group } \\
\qquad n=57\end{array}$ \\
\hline \multicolumn{3}{|l|}{ marital status } \\
\hline married & $62 \%$ & $60 \%$ \\
\hline unmarried partnership & $12 \%$ & $12 \%$ \\
\hline divorced $r$ & $13 \%$ & $11 \%$ \\
\hline \multicolumn{3}{|l|}{ education } \\
\hline 9-year elementary school & $30 \%$ & $30 \%$ \\
\hline middle school & $28 \%$ & $28 \%$ \\
\hline high school & $23 \%$ & $25 \%$ \\
\hline \multicolumn{3}{|l|}{ highest professional education } \\
\hline apprenticeship & $38 \%$ & $41 \%$ \\
\hline technical school & $20 \%$ & $16 \%$ \\
\hline university degree & $17 \%$ & $13 \%$ \\
\hline \multicolumn{3}{|l|}{ employment at diagnosis } \\
\hline full time & $28 \%$ & $25 \%$ \\
\hline at least half time & $16 \%$ & $25 \%$ \\
\hline housewife & $13 \%$ & $18 \%$ \\
\hline retired & $21 \%$ & $18 \%$ \\
\hline \multicolumn{3}{|c|}{ reporting change in eating habits } \\
\hline at baseline, $\mathrm{T1}$ & $48 \%$ & $42 \%$ \\
\hline after rehab treatment, $\mathrm{T} 2$ & $88 \%$ & $64 \%$ \\
\hline
\end{tabular}

- Fig. 2 demonstrates that the behavior of this parameter is very similar to FV: TFV intake is similar for both groups at baseline and in the intervention group increases rapidly at $\mathrm{T} 2$ with small decrements at T3 and T4 without returning to the baseline. TFV in the control group does not change over time. Analysis by ANOVA (as for FV above) yields results identical to those reported for FV intake. 
Table 3 Mean intake of fruit and vegetables [g/day].

\begin{tabular}{|c|c|c|}
\hline & $\begin{array}{l}\text { Intervention group * } \\
\mathbf{n}=61\end{array}$ & $\begin{array}{l}\text { Control group } \\
n=57\end{array}$ \\
\hline T1 = baseline & $483 \pm 235$ & $460 \pm 177$ \\
\hline T2 = 1 month & $743 \pm 287^{*}$ & $526 \pm 177 \S$ \\
\hline T3=3 months & $673 \pm 246 * \#$ & $485 \pm 169^{\S}$ \\
\hline T4 = 6 months & $631 \pm 222 * \#$ & $505 \pm 172^{\S}$ \\
\hline $\begin{array}{l}\text { § Data between gr } \\
\text { * Data differ signif } \\
\text { \# Data differ signif }\end{array}$ & $\begin{array}{l}\text { rese significantly different b } \\
\text { rom } \mathrm{T} 1 \text { = baseline } \\
\text { rom } \mathrm{T} 2\end{array}$ & \\
\hline
\end{tabular}



Fig. 2 Intake of fruit and vegetables without juices or jams (circles) and total fruit and vegetables (squares) in control subjects (open symbols) and in participants in the intervention group (filled symbols) as reported in the 4-day food records at $\mathrm{T} 1=$ before, $\mathrm{T} 2=4$ weeks after, $\mathrm{T} 3=3$ months after, and T4 $=6$ months after the begin of the study. Data are given as means \pm SEM.

\section{Percentage of patients who met the aim of $>650 \mathrm{~g} / \mathrm{d}$ FV}

The percentage of patients consuming more than $650 \mathrm{~g} / \mathrm{d}$ of FV was low and similar in both groups at baseline (CON 18\%, INT $25 \%)$. While there was an increase in this percentage in the control group at T2 (30\%), at T3 and T4 the baseline situation was reached again. In the intervention group a significantly higher percentage of patients consumed $>650 \mathrm{~g} / \mathrm{d}$ of $\mathrm{FV}$ at all follow-up time points T2-T4 with values between 49 and 54\%, i.e., twice the values at baseline ( $\bullet$ Table 4).

\section{Total energy and fat intake}

Total energy intake did not change significantly within the groups between T1 and T4. Analysis by ANOVA reported a significantly higher energy intake in the intervention group, but post-hoc testing identified only a difference between groups at T3, thus marginalizing the relevance of this finding ( $\bullet$ Table 5). Fat intake did not differ between groups; however, in the intervention group all follow-up data were lower than at baseline, while in the control group only fat intake at T3 was lower than at baseline ( $\bullet$ Table 5$)$.

\section{Refresher courses}

Refresher courses after 3 and 6 months were attended by 41 and 29 patients, respectively. 27 patients visited both, 43 at least one and 18 patients attended no refresher course. FV intake at T4=6
Table 4 Percentage of patients consuming $>650 \mathrm{~g}$ fruit and vegetables per day.

\begin{tabular}{|lll} 
& $\begin{array}{l}\text { Intervention group } \\
\mathbf{n = 6 1}\end{array}$ & $\begin{array}{l}\text { Control group } \\
\mathbf{n = 5 7}\end{array}$ \\
\hline $\mathbf{T 1}=$ baseline & 24.6 & 17.5 \\
$\mathbf{T} \mathbf{2}=\mathbf{1}$ month & $54.1^{*}$ & 29.8 \\
$\mathbf{T} 3=3$ months & $52.5^{*}$ & 14.0 \\
\hline T4=6 months & $49.2^{*}$ & 17.5 \\
\hline
\end{tabular}

* indicates significant difference $(p<0.01)$ from baseline value within the respective group

Table 5 Energy and fat intake.

\begin{tabular}{|c|c|c|c|c|}
\hline & \multicolumn{2}{|c|}{ Energy intake [kcal/d] } & \multicolumn{2}{|c|}{ Fat intake [ $\%$ of total energy] } \\
\hline & $\begin{array}{l}\text { Intervention } \\
\qquad \mathbf{n = 6 1}\end{array}$ & $\begin{array}{c}\text { Control } \\
n=57\end{array}$ & $\begin{array}{l}\text { Intervention } \\
\qquad n=61\end{array}$ & $\begin{array}{c}\text { Control } \\
n=57\end{array}$ \\
\hline T1 = baseline & $2002 \pm 440$ & $1868 \pm 492$ & $36 \pm 6$ & $36 \pm 6$ \\
\hline $\mathrm{T} 2=1$ month & $1941 \pm 474$ & $1788 \pm 429$ & $31 \pm 5^{\#}$ & $34 \pm 6$ \\
\hline T3 = 3 months & $2022 \pm 520^{*}$ & $1792 \pm 395$ & $33 \pm 6^{\# \S}$ & $33 \pm 5^{\#}$ \\
\hline T4 = 6 months & $1993 \pm 553$ & $1852 \pm 438$ & $33 \pm 6^{\# \S}$ & $35 \pm 5$ \\
\hline
\end{tabular}

months for patients attending at least one $(661 \pm 205 \mathrm{~g} / \mathrm{d})$ or no refresher course $(607 \pm 236 \mathrm{~g} / \mathrm{d})$ did not differ significantly.

\section{Discussion}

$\nabla$

Insulin sensitivity may be one of the major factors modulating cancer development and progression [25] and it is influenced by body weight and physical activity. Plant foods have been shown to reduce the risk of metabolic syndrome $[15,16]$ and the risk of breast cancer recurrence $[7,13,14]$. Our structured 2-week nutritional training program was aimed at increasing the consumption of plant foods in women with early breast cancer and it successfully raised the intake of fruits and vegetables to the recommended level [20] for a follow-up period of 6 months.

Our data appear to be representative of the effect in women with early breast cancer. Subjects were invited without previous screening to participate in the study, some $68 \%$ of the invited subjects could be randomized with exclusions mainly due to subjects declining or failing the inclusion criteria, and $78 \%$ of the randomized subjects entered the final analysis. The drop-out rate was slightly higher in the intervention group (20\%) than in the control group (14\%), and this may have increased the effect size.

Major intervention trials aimed at changing eating habits have arrived at similar or smaller effect sizes as those observed in the present study. Pierce and co-workers in the large randomized WHEL trial used in a multimodal approach telephone counseling in combination with cooking classes and newsletters to increase the intake of vegetables and fruit from about 7 to 11 servings per day [26]. Assuming a serving size of about $80 \mathrm{~g}$, this corresponds to an intake of some $880 \mathrm{~g}$, very similar to the average of $874 \mathrm{~g}$ of total fruit and vegetables reached at 6 months in our intervention group. As reported for the Women's Health Initiative Randomized Controlled Dietary Modification Trial group-based nutritional training including 18 sessions per year increased the intake of fruit and vegetables from 3.6 to 5.1 servings per day (equivalent to some $400 \mathrm{~g} / \mathrm{d}$ ) [27]. Our compact 2 week program invested $17 \mathrm{~h}$ of training in groups of 5-10 women or some $2.5 \mathrm{~h}$ 
per participant. This compares well with similar time requirements in the WHEL trial (18 phone calls per year) [28] and in the Women's Health Initiative (18 group sessions of 8-15 participants per year) [27]. The WINS trial aiming at reducing dietary fat intake invested much more time including $8 \mathrm{~h}$ of individual counseling [29]. Recently, a nutrition education program to promote a Mediterranean diet was presented requiring 15 weeks of intensive training and 100 weeks of consolidation [30].

The study was not designed to monitor outcome parameters but nutritional intake. Thus, the aim was to prove the effectivity of the training program to reliably change the eating behavior of the participants. While this was achieved, it remains to be shown that the induced dietary changes are associated with a relevant clinical benefit.

The refresher courses in our study were offered on a voluntary basis and did not significantly change mean fruit and vegetable consumption when comparing patients participating or not participating in these courses. Still, since this was not a primary objective of the study, it cannot be ruled out that the refresher courses contributed to stabilizing vegetable and fruit intake at a high level. However, the initial intensive training during rehabilitation appears to be the key factor in changing eating habits. This corresponds to the observations of others, who also observed long-term adherence to initial counseling in studies aiming at low-fat and/or high-FV eating patterns [22,26,31-33]. The training program was designed to be easily implementable in different health care settings. The theoretical units were developed including written material to clearly present relevant nutrition facts, to engage and involve the participants to envision their situations at home and to creatively evaluate potential paths to change their and their families eating behavior lastingly. To increase motivation was a major aim in each unit.

Cookery classes similarly were aimed at demonstrating the feasibility of the projected changes and to support the elements of pleasure in following the proposed eating patterns. Implementing the program at several institutions would be a prerequisite for a multicenter study to test for the clinical relevance of this nutritional training.

Since the $17 \mathrm{~h}$ of the complete program are divided into small individual modules, the program can be spread over a 2 week period and leave enough time to be combined with a similar training aimed at increasing physical exercise or stress control.

We are well aware that the reported fruit and vegetable intake was not controlled using biomarkers (e.g. serum concentrations of carotenoids) and we therefore had to rely on the data the patients noted in the 4-day food records. However, comparable studies found a direct and strong association between the amount of self-reported fruit and vegetable intake and serum levels of carotenoids [34-37]. In breast cancer survivors there is a 2-fold risk of underreporting energy intake by women with a body mass index $>30 \mathrm{~kg} / \mathrm{m}^{2}$ [38]. However, this risk of bias was similar in both study groups with 6 and 5 participants having a $\mathrm{BMI}>30 \mathrm{~kg} / \mathrm{m}^{2}$ in the intervention and control group, respectively. To our knowledge there are also no data suggesting an overreporting of fruit and vegetable intake in breast cancer patients with intensive dietary support. Therefore, we feel it was justified to use the food record data to estimate actual dietary intake. In conclusion, this short modular training program has been shown to successfully modulate dietary habits of cancer patients in the intended direction. The program is easy to teach and might be implemented without major difficulties in other institutions.
The program is intended to be combined with other training modules aiming at physical exercise and stress reduction to modulate typical Western lifestyle patterns more comprehensively.

\section{Acknowledgements}

$\nabla$

The authors' responsibilities were as follows - JA, ST, JS and HHB designed the study; ST and JA conducted the research program and analyzed the data; JA and ST wrote the manuscript with critical input from JS and HHB; JA had primary responsibility for the final content. ST received a grant from the Fördergesellschaft Forschung Tumorbiologie, Freiburg, Germany. No conflicts of interest were reported.

The authors kindly thank the Foerdergesellschaft Forschung Tumorbiologie, Freiburg, Germany, which supported this project with a grant, and Abigail Dossett, Jennifer Friedmann, Dagmara Jedrasiak and Anja Boehmler for their assistance with the documentation and computing of the data.

\section{References}

1 American Cancer Society. Breast Cancer Facts \& Figures 2009-2010. Atlanta, Georgia, USA: America Cancer Society, Inc, 2010

2 World Cancer Research Fund, American Instute for Cancer Research (ed.). Food, Nutrition, Physical Activity and the Prevention of Cancer: a Global Perspective. Washington, DC, USA: American Institute for Cancer Research, 2007

3 Goodwin PJ, Ennis M, Pritchard KI et al. Fasting insulin and outcome in early-stage breast cancer: results of a prospective cohort study. J Clin Oncol 2002; 20: 42-51

4 Patel AV, Callel EE, Bernstein L et al. Recreational physical activity and risk of postmenopausal breast cancer in a large cohort of US women. Cancer Causes Control 2003; 14: 519-529

5 Bernstein L, Patel AV, Ursin G et al. Lifetime recreational exercise activity and breast cancer risk among black women and white women. J Natl Cancer Inst 2005; 97: 1671-1679 doi:10.1093/jnci/dji374

6 Holmes MD, Chen WY, Feskanich $D$ et al. Physical activity and survival after breast cancer diagnosis. JAMA 2005; 293: 2479-2486 doi:10.1001/jama.293.20.2479

7 Gold EB, Pierce JP, Natarajan L et al. Dietary pattern influences breast cancer prognosis in women without hot flashes: the women's healthy eating and living trial. J Clin Oncol 2009; 27: 352-359 doi:10.1200/ JCO.2008.16.1067

8 Smith-Warner SA, Spiegelman D, Yaun SS et al. Intake of fruits and vegetables and risk of breast cancer: a pooled analysis of cohort studies. JAMA 2001; 285: 769-776

9 Irwin ML, Duggan C, Wang C-Y et al. Fasting C-peptide levels and death resulting from all causes and breast cancer: the health, eating, activity, and lifestyle study. J Clin Oncol 2011; 29: 47-53 doi:10.1200/ JCO.2010.28.4752

10 Rock CL, Demark-Wahnefried W. Nutrition and survival after the diagnosis of breast cancer: a review of the evidence. J Clin Oncol 2002; 20: 3302-3316

11 Riboli E, Norat T. Epidemiologic evidence of the protective effect of fruit and vegetables on cancer risk. Am J Clin Nutr 2003; 78: 559S-569S

12 Van Gils CH, Peeters PHM, Bueno-de-Mesquita HB et al. Consumption of vegetables and fruits and risk of breast cancer. JAMA 2005; 293: 183-193 doi:10.1001/jama.293.2.183

13 Rock CL, Flatt SW, Natarajan L et al. Plasma carotenoids and recurrence-free survival in women with a history of breast cancer. J Clin Oncol 2005; 23: 6631-6638 doi:10.1200/JCO.2005.19.505

14 Pierce JP, Stefanick ML, Flatt SW et al. Greater survival after breast cancer in physically active women with high vegetable-fruit intake regardless of obesity. J Clin Oncol 2007; 25: 2345-2351 doi:10.1200/ JCO.2006.08.6819

15 Babio N, Bulló M, Salas-Salvadó J. Mediterranean diet and metabolic syndrome: the evidence. Public Health Nutr 2009; 12: 1607-1617 doi:10.1017/S1368980009990449

16 Høstmark AT. The Oslo Health Study: a Dietary Index estimating high intake of soft drinks and low intake of fruits and vegetables was positively associated with components of the metabolic syndrome. Appl Physiol Nutr Metab 2010; 35: 816-825 doi:10.1139/h10-080 
17 Salminen E, Heikkilä S, Poussa $T$ et al. Female patients tend to alter their diet following the diagnosis of rheumatoid arthritis and breast cancer. Prev Med 2002; 34: 529-535 doi:10.1006/pmed.2002.1015

18 Demark-Wahnefried $W$, Peterson B, McBride $C$ et al. Current health behaviors and readiness to pursue life-style changes among men and women diagnosed with early stage prostate and breast carcinomas. Cancer 2000; 88: 674-684

19 Reuss-Borst M, Kötter J, Hartmann U et al. Nutrition patterns in German breast cancer patients. Dtsch Med Wochenschr 2011; 136: 575581 doi:10.1055/s-0031-1274541

20 Deutsche Gesellschaft für Ernährung. Referenzwerte für die Nährstoffzufuhr. Frankfurt am Main: Umschau Buchverlag, 2000

$21 \mathrm{Hu}$ FB, Rimm E, Smith-Warner SA et al. Reproducibility and validity of dietary patterns assessed with a food-frequency questionnaire. Am J Clin Nutr 1999; 69: 243-249

22 Chlebowski RT, Blackburn GL, Buzzard IM et al. Adherence to a dietary fat intake reduction program in postmenopausal women receiving therapy for early breast cancer. The Women's Intervention Nutrition Study. J Clin Oncol 1993; 11: 2072-2080

23 Kluthe B, Kassel P. PRODI - Ernährungs- und Diätberatungssoftware. Stuttgart: Wissenschaftliche Verlagsgesellschaft, 2001

24 SPSS. Statistical packages for social sciences. München: 2001

25 Arends J. Metabolism in cancer patients. Anticancer Res 2010; 30: 1863-1868

26 Pierce JP, Newman VA, Flatt SW et al. Telephone counseling intervention increases intakes of micronutrient- and phytochemical-rich vegetables, fruit and fiber in breast cancer survivors. J Nutr 2004; 134: 452-458

27 Prentice RL, Caan B, Chlebowski RT et al. Low-fat dietary pattern and risk of invasive breast cancer: the Women's Health Initiative Randomized Controlled Dietary Modification Trial. JAMA 2006; 295: 629642 doi:10.1001/jama.295.6.629

28 Pierce JP, Newman VA, Natarajan L et al. Telephone counseling helps maintain long-term adherence to a high-vegetable dietary pattern. J Nutr 2007; 137: 2291-2296
29 Chlebowski RT, Blackburn GL, Thomson CA et al. Dietary fat reduction and breast cancer outcome: interim efficacy results from the Women's Intervention Nutrition Study. J Natl Cancer Inst 2006; 98: 1767-1776 doi:10.1093/jnci/djj494

30 Panunzio MF, Caporizzi R, Antoniciello A et al. Randomized, controlled nutrition education trial promotes a Mediterranean diet and improves anthropometric, dietary, and metabolic parameters in adults. Ann Ig 2011; 23: 13-25

31 Simon MS, Heilbrun $L K$, Boomer A et al. A randomized trial of a lowfat dietary intervention in women at high risk for breast cancer. Nutr Cancer 1997; 27: 136-142

32 Holm LE, Nordevang E, Ikkala E et al. Dietary intervention as adjuvant therapy in breast cancer patients - a feasibility study. Breast Cancer Res Treat 1990; 16: 103-109

33 Boyd NF, Martin LJ, Beaton M et al. Long-term effects of participation in a randomized trial of a low-fat, high-carbohydrate diet. Cancer Epidemiol Biomarkers Prev 1996; 5: 217-222

34 Rock CL, Flatt SW, Wright FA et al. Responsiveness of carotenoids to a high vegetable diet intervention designed to prevent breast cancer recurrence. Cancer Epidemiol Biomarkers Prev 1997; 6: 617-623

35 McEligot AJ, Rock CL, Flatt SW et al. Plasma carotenoids are biomarkers of long-term high vegetable intake in women with breast cancer. J Nutr 1999; 129: 2258-2263

36 Le Marchand L, Hankin JH, Carter FS et al. A pilot study on the use of plasma carotenoids and ascorbic acid as markers of compliance to a high fruit and vegetable dietary intervention. Cancer Epidemiol Biomarkers Prev 1994; 3: 245-251

37 Pierce JP, Natarajan L, Sun S et al. Increases in plasma carotenoid concentrations in response to a major dietary change in the women's healthy eating and living study. Cancer Epidemiol Biomarkers Prev 2006; 15: 1886-1892 doi:10.1158/1055-9965.EPI-05-0928

38 Caan BJ, Flatt SW, Rock CL et al. Low-energy reporting in women at risk for breast cancer recurrence. Women's Healthy Eating and Living Group. Cancer Epidemiol Biomarkers Prev 2000; 9: 1091-1097 